Acta Poetica 25-1

PRIMAVERA

2004

\title{
Traducir: la tarea infinita o cómo todo tiene que cambiar para que todo quede igual
}

\author{
Elke Wehr
}

Partiendo de la experiencia de la autora como traductora del francés, del italiano y del español al alemán, en estas páginas se hacen algunas reflexiones personales en torno a la idea de la traducción como actividad generalizada: como lectura de lo vivido o lo escuchado, como interpretación o como escritura de la experiencia de otro, pero también como viaje e intercambio. Se compara al traductor con el actor, con el imitador de voces y con el ilusionista que, además de ser un artista de la desaparición, añade un nivel más a la ficción con la cual, de entrada, trabaja. Se formulan también algunas preguntas que apuntan hacia una ética de la traducción: ¿Es posible - y aun legítimo- apropiarse de lo ajeno, hacerlo propio? ¿Debemos conservar lo ajeno y forzar la propia lengua a fin de que pueda recibirlo?

Based on the author's experience as a translator from the French, Italian and Spanish into the German language, this essay explores, from a rather personal point of view, the idea of translation as a pervasive activity: as a way of "reading" what has been lived or heard, as interpretation or as a way of writing someone else's experience, and also as travel and exchange. The translator is compared to the actor, to the imitator of voices and to the ilusionist who, in addition to being an artist of disappearance, adds one more level to the fiction with which he already works. Some questions are also posed that suggest an ethics of translation: Is it possible or even legitimate - to appropriate what is foreign, to make it ours? Should we keep what is foreign and strain our mother tongue so that she can receive it? 


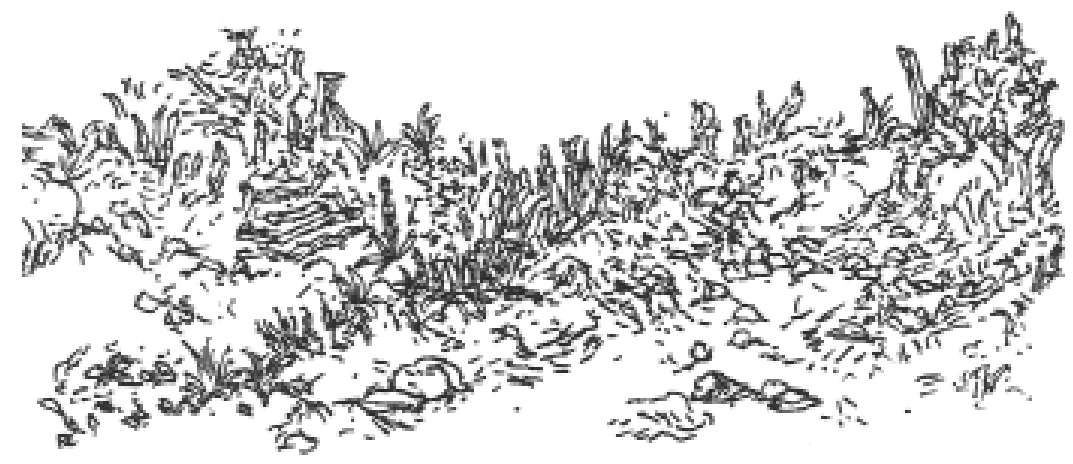


Acta Poetica 25-1

PRIMAVERA

2004

Elke Wehr

Traducir: la tarea infinita o cómo todo tiene que cambiar para que todo quede igual

Nos pasamos todos la vida traduciendo... Traducimos las palabras escuchadas o leídas, traducimos nuestros pensamientos, nuestras emociones y percepciones en palabras, traducimos los gestos del otro en palabras, hacemos una lectura de lo vivido, o sea una traducción. Todo texto escrito es ya una traducción. También este texto. El traductor profesional es el que cobra por este trabajo.

El trabajo del traductor - literario, se entiende- empieza cuando todo ha terminado, todo está ya hecho. Se inclina sobre un cuerpo muerto, no, más bien durmiente, y lo despierta en otra lengua. El autor trabaja con el caos y lo ordena en una continua lucha con sus fantasmas. El traductor trabaja sobre y con la lengua pura, luchando también con otro tipo de fantasmas, en el infierno de las palabras, que para nada es un infierno menor, azotado como está por la duda, la mala conciencia, el sentimiento de impostura: la tarea imposible. Un infierno que también es paraíso, claro. La dicha de un traslado logrado. Un transporte feliz. Mientras tanto, en este movimiento de idas y venidas entre esos mundos opuestos, el traductor se encuentra en una especie de tierra de nadie, en un entre-espacio 
que sólo existe en su mente: con un pie en cada lengua, en dos universos con todas sus implicaciones formales, estéticas, culturales etc., o, como lo dice el alemán en una expresión muy gráfica: en cada orilla de un río, porque la palabra Übersetzer/ traductor tiene dos lecturas: es también el barquero que lleva su mercancía de una orilla a la otra, cruzando ese río entre dos lenguas, esa nada. Aun siendo una imagen un poco recurrente, sigue gustándome. Porque implica la idea del viaje. Así va el traductor, con su bagaje de palabras, y en este viaje se pierden cosas y se encuentran cosas, se ve la mercancía empobrecida y enriquecida a la vez, y cuando el texto-mercancía llega a la otra orilla, después de infinitos golpes de remo de parte del transportador o transbordador, ha cambiado completamente de forma, ni una coma sigue en su sitio, y si sigue en su sitio es una coma alemana, seria e inamovible, es otra y es igual... ¿o no? Idéntica no puede ser. ¿Qué sería? ¿Un mellizo? ¿Es el texto que hubiera escrito el autor si hubiera sido capaz de escribirlo en la lengua del traductor (en mi caso en alemán)? ¿Habría podido hacerlo? ¿Tendrían sus palabras las mismas cargas, las mismas connotaciones, la misma aura, etc., que las mías, directamente salidas de mi mente alemana? ¿Y sería posible una traducción al revés, una re-traducción al idioma del autor, reconstruyendo ese "original" ficticio que nunca existió? Aquí entramos en un juego borgiano de espejos, otra lectura más de Pierre Menard...

Pero no vamos tan mal encaminados. El traductor es algo así como el lector ideal, el lector, como lo veía Borges, libre, recreador, acabador del texto. El traductor es el lector cuya lectura toma forma de traducción. Y cada texto tiene tantas lecturas como tiene lectores. O sea, infinitas traducciones. Estamos hablando, se entiende, de textos que pasan la prueba de la traducción. Un texto "malo", digámoslo así de sencillo, se desmorona en seguida en esta prueba, en este proceso de deconstrucción y reconstrucción. Y hablamos, también en este 
caso, de textos en prosa; la traducción de poesía obedece a otras reglas.

Ahora bien, ¿qué hace el traductor? Es un ilusionista que se suprime a sí mismo en el texto y, sin embargo, de alguna manera, queda presente. Algunos más que otros. Si un traductor es a la vez escritor, sobre todo si es conocido y famoso, se le tolera, en general, más presencia. Eso se dijo de (y también se reprochó a) Paul Celan: que todas sus traducciones, sobre todo de poesía, eran celanianas. A un traductor "corriente", por bueno que sea, no se le perdona este primer plano: somos actores, no autores, o sea que pendemos de una letra, valga la expresión...

Mi padre era actor. A mí me tocó a lo largo de toda mi infancia y parte de mi juventud trabajar con él por las tardes, memorizar con él sus textos. Me crié en el teatro, entre palabras y decorados, me sabía todo de memoria, y por si esto no fuera suficiente, me leí, de niña, libros tan absurdos como Cien piezas de un acto o toda la obra de Jean Anouilh. Creo que ahí empezó todo. Pero nadie, de joven, quiere ser traductor. Eso viene más tarde, como producto de otra cosa, de la cosa literaria en sí. Lo que sí hice en estos años "de formación" fue acumular un tesoro sin saberlo. A los veinte años, viviendo en París, después de haber leído un cuento de Camus, lo traduje porque quería saber cómo sonaba en alemán. Y desde entonces ya no he parado. Es un vicio.

Pero volvamos a los actores. La traducción, tarea paradójica si las hay, siempre ha sido comparada con otras actividades interpretativas, como si no se sostuviera por sí misma, como si siempre fuera necesario este "como". Suelen cojear de algún pie esas comparaciones. Sin embargo, puestos a comparar, por obvias razones biográficas y otras más, me gusta y me convence más la comparación del traductor con el actor (a otros traductores les gusta compararse con un músico y considerar el original como una especie de partitura, yo no iría tan lejos). 
Somos actores "de carácter", somos imitadores de voces, tenemos que dominar todos los registros imaginables, los tonos, medio tonos, cuartos de tono; somos, a un tiempo, todos los personajes de un texto, incluido el narrador. También somos ilusionistas, como ya dije: no sólo porque somos artistas de la desaparición, por lo menos hasta cierto punto, sino también porque añadimos otra ficción más a la ficción con la que trabajamos: la ficción del lector que cree leer una novela de Vargas Llosa, pongamos por caso, de la que Vargas Llosa no ha escrito ni una sola palabra.

Las palabras no son equivalentes, no existe le mot juste en la traducción; los textos sí pueden serlo. Siempre me ha gustado mucho esa anécdota de un campesino italiano al que no sé qué científicos le hicieron unas preguntas de tipo lingüístico, a las que contestó que sí, que podía imaginar perfectamente que había otras lenguas con otras palabras, en las que el cielo, por ejemplo, se llamase de otra manera, y así todas las demás, pero, eso sí, "il pane è il pane”. También yo sé que "il pane è il pane”, y sin embargo tengo que traducir pan por Brot, y ya estamos en otro mundo de asociaciones, de usos, costumbres y hechos culturales. Son dos ideas de pan completamente diferentes, hasta se excluyen. Ese ejemplo, por sencillo que parezca, encierra toda la problemática de la traducción y de su posibilidad e imposibilidad. ¿Cómo se puede sustituir una lengua por otra? ¿Es posible - y legítimo - apropiarse de lo ajeno, hacerlo propio? ¿Debemos conservar lo ajeno y forzar la propia lengua para que pueda recibirlo? ¿Qué hace un amigo mío, traductor al chino, cuando traduce la frase "le regaló un Porsche" por "le regaló una bicicleta"? Aquí nos topamos con la vieja pregunta: ¿acercamos el texto al lector o pedimos al lector que haga el esfuerzo de acercarse, que sea él quien viaje? Son preguntas que acompañan siempre el trabajo del traductor, explícita o implícitamente. En la práctica solemos hacer una especie de mezcla de ambas tendencias. En la historia 
de la traducción al alemán, un ejemplo de la primera sería la traducción que hizo Schlegel de Shakespeare; y de la segunda, la traducción de Sófocles hecha por Hölderlin, que tradujo al autor clásico a una especie de alemán "griego". Una traducción verdaderamente lograda o congenial, que ha conseguido esta alquimia entre lo ajeno y lo propio, nos da la impresión, mientras la leemos, que leemos dos textos, que sabemos la lengua en la que fue escrito el original.

La práctica y la teoría. A la hora de traducir no hay teoría que valga. Estamos solos delante del texto. Lo dejó bien claro mi colega Dieter Zimmer, traductor de Nabokov y Borges, entre otros. Los conocimientos de la teoría de la traducción son, a la hora de traducir, tan útiles como los conocimientos aerodinámicos para preparar un asado en el horno. Cada texto comporta o impone su propia teoría; con esa teoría trabajamos a menudo sin darnos cuenta, sin ser plenamente conscientes de ello. Hasta se podría decir que aplicamos una teoría a una frase para descartarla en la siguiente. Cada trabajo de traducción implica constantes decisiones conscientes e inconscientes, somos ciempiés y trabajamos, en partes más o menos iguales, con el sentimiento y las emociones, y con el conocimiento, el saber, el intelecto, y eso es uno de los atractivos, uno de los placeres de este quehacer absurdo - absurdo porque sabemos que nunca vamos a llegar a ese "cien por ciento" del texto original, nunca vamos a lograr que la lectura de la traducción produzca el mismo efecto en el lector que la del original-. Cada traducción es un nuevo intento de acercamiento a este ideal... un intento que sabemos efímero. Sentimiento e intelecto quieren decir también que trabajamos con la lengua en mayúsculas y con la lengua en minúsculas, que nos encontramos siempre en un universo de referencias literarias cruzado por otro de referencias personales, algo así como el uso personal del idioma, lo propio, hecho de vivencias y lecturas. Los traductores no somos copistas, o sea meros esclavos del original: 
somos imitadores de voces justamente por tener una voz propia. Sin ese "yo" soberano, que en el mejor de los casos es un cómplice del autor, que participa, como él, en la eterna conversación de los libros, no puede haber un texto consistente, un texto que "vive".

Mi lengua, el alemán, es un buen "recipiente". Hasta me parece un recipiente ideal para ese trasvase que es la traducción. Que se me perdone este asomo de orgullo lingüístico: no hace daño mientras me ayude en esta tarea infinita e imposible. Pero eso no quiere decir que mi lengua "embellezca" el original, que lo ennoblezca, sino que es una lengua que, en su casi infinita flexibilidad, se amolda perfectamente al texto de origen. El alemán siempre ha recibido los afluentes de otras lenguas, hasta tal punto que la famosa traducción de Shakespeare por Schlegel hizo que a este último se le considere como el tercer clásico alemán, al lado de Goethe y Schiller. El alemán, la lengua filosófica por antonomasia, la lengua "de los poetas y pensadores", tiene esa vertiente cartesiana, de exactitud, de concreción, de determinación, de lógica, que no tiene el español, y que me obliga a veces a darle un "peso" al texto que no tiene en su versión original; pero también tiene su vertiente barroca, aunque sea un barroco pasado por las luces de la Ilustración. El español no pasó por ese proceso, sigue conservando cierta retórica, cierto uso barroco de la metáfora (si Lutero hubiera sido español, habría vertido la Biblia al español de Sancho Panza). Por eso, un español se siente todavía cerca del Quijote, de la lengua del Quijote, más cerca de lo que puede sentirse un alemán de un texto alemán del siglo xvII. Sin embargo, creo que el español, "convirtiéndose" al alemán, despierta el alma barroca de mi lengua, sobre todo en sus variantes hispanoamericanas.

Después de traducir durante largos años del francés y del italiano, el español fue para mí un descubrimiento tardío. Y me quedé con él. He encontrado la pareja perfecta. Vivir en 
España, desde hace 17 años, me ha dado una mirada sobre el alemán que, no siendo la de una extranjera, ni mucho menos, me ha procurado cierta distancia, un paso atrás, una mirada que me deja verlo mejor, hasta diría con atisbos de asombro en algunos casos. No se trata de una equidistancia entre las dos lenguas, pero sí tiene algo de ese ir y venir, de ese terreno incierto en el que se mueve el traductor. Y ya me moví tanto que yo misma entré en el reino de la ficción. Si ustedes quieren viajar al Reino de Redonda, que es una isla real del Caribe y un reino ficticio cuyo rey se llama Xavier I y en la vida real Javier Marías, no duden en pedirme el visado: soy cónsul por nombramiento real (en los dos sentidos) en Berlín oriental, por más señas antigua capital de un país que también se está volviendo más y más ficción. 